\section{Endoscopic ultrasound-guided transmural drainage of a pancreatic collection: case report of a massive hemoperitoneum without intracystic bleeding}

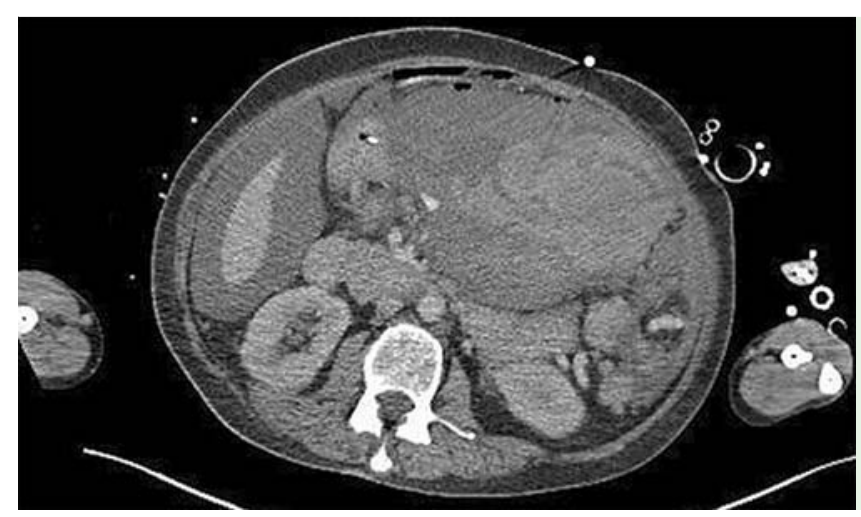

Fig. 1 Computed tomographic scan shows a massive hemoperitoneum without intracystic bleeding and with strictly intraperitoneal active bleeding.

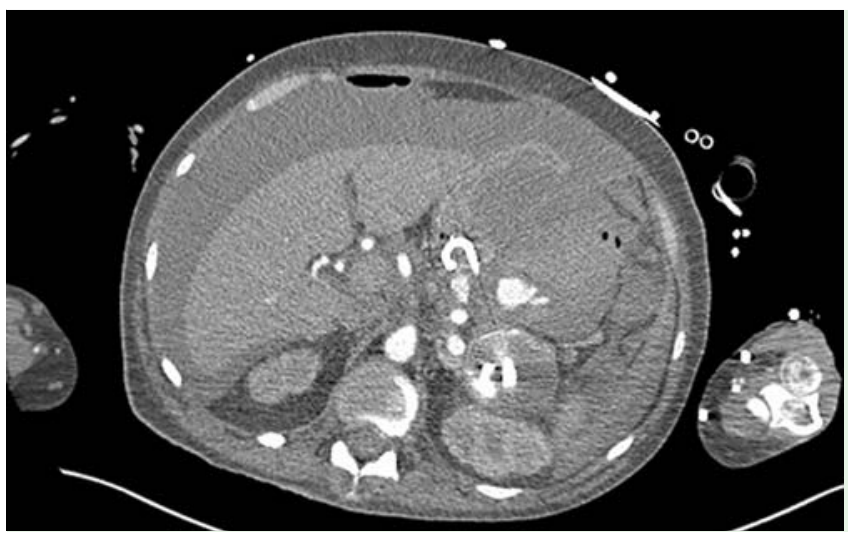

Fig. 2 The source of the bleeding is at point of puncture of the cystogastrostomy, at the level of the gastric wall.

A 51-year-old woman was referred for the management of a painful pseudocyst, $50 \mathrm{~mm}$ in diameter, in the tail of the pancreas. The pseudocyst had mature walls and was close to the gastrointestinal lumen [1]. The patient had no ascites and no coagulation disorder. Segmental portal hypertension was noted on computed tomographic examination.

A cystogastrostomy was done with a 10-Fr cystotome, and two 7-Fr, 7-cm plastic prostheses were introduced after dilation of the orifice with an 8-mm balloon. There were no operative adverse events. In the recovery room, the patient developed hemodynamic instability, with a hemoglobin level of $4.5 \mathrm{~g} / \mathrm{dL}$.

An angioscan revealed a massive hemoperitoneum with strictly intraperitoneal active bleeding ( $\nabla$ Fig. 1 ). An emergency caudal splenopancreatectomy was performed. The source of the bleeding was at a distance from the point of puncture of and safe procedure, with a median success $13 \%$, and a mortality rate of $0.3 \%$ [2]. Major adverse events are bleeding, pneufistula, stent migration and tract dehisand air embolism [3-5].

Although hemorrhage is a well-known complication, this is the first described a distance from the

intracystic bleeding, or direct trauma to an interposed vessel. We suspect laceration of a vessel located in the intraperitoneal gastric wall, secondary to the balloon dilation. Awareness is necessary, and excessive dilation should be avoided in a patient with segmental portal hypertension who is undergoing EUS-guided transmural drainage of a pancreatic collection.

Endoscopy_UCTN_Code_CPL_1AL_2AD

Competing interests: None

Sébastien Godat, Fabrice Caillol, Erwan Bories, Christian Pesenti, Jean Philippe Ratone, Marc Giovannini

Division of Gastroenterology,

Paoli-Calmettes Institute, Marseille, France

\section{References}

1 Seewald S, Ang TL, Teng KC et al. EUS-guided drainage of pancreatic pseudocysts, abscesses and infected necrosis. Dig Endosc 2009; 21 (Suppl. 01): S61 -S65

2 Dumonceau JM, Macias-Gomez C. Endoscopic management of complications of chronic pancreatitis. World J Gastroenterol 2013; 19: 7308-7315

3 Singhal S, Rotman SR, Gaidhane M et al. Pancreatic fluid collection drainage by endoscopic ultrasound: an update. Clin Endosc 2013; 46: 506- 514

4 Varadarajulu S, Christein JD, Wilcox CM. Frequency of complications during EUS-guided drainage of pancreatic fluid collections in 148 consecutive patients. J Gastroenterol Hepatol 2011; 26: 1504-1508

5 Puri R, Mishra SR, Thandassery RB et al. Outcome and complications of endoscopic ultrasound guided pancreatic pseudocyst drainage using combined endoprosthesis and naso-cystic drain. J Gastroenterol Hepatol 2012; 27: $722-727$

\section{Bibliography}

Dol http://dx.doi.org/

$10.1055 / \mathrm{s}-0034-1391858$

Endoscopy 2015; 47: E244

(c) Georg Thieme Verlag KC

Stuttgart · New York

ISSN 0013-726X rate of $89 \%$, an average morbidity rate of moperitoneum, and infection. Rarer adverse events are pancreatitis, pancreatic cence, Ogilvie syndrome, pneumothorax, case of hemoperitoneum without rupture,

\section{Corresponding author}

\section{Sébastien Godat, MD}

Division of Gastroenterology

Paoli-Calmettes Institute

232, boulevard Sainte Marguerite - BP 156

13273 Marseille Cedex 9

France

Fax: +33-4-91223658

tagodat@gmail.com 